\title{
Текстовая модальность как способ ценностного представления Тувы в немецкой публицистике
}

\author{
Людмила В. Комуцци \\ Севастопольский государственный университет, Российская Федерация, \\ Ирина В. Карпунина \\ Белгородский государственный университет, Российская Федерация
}

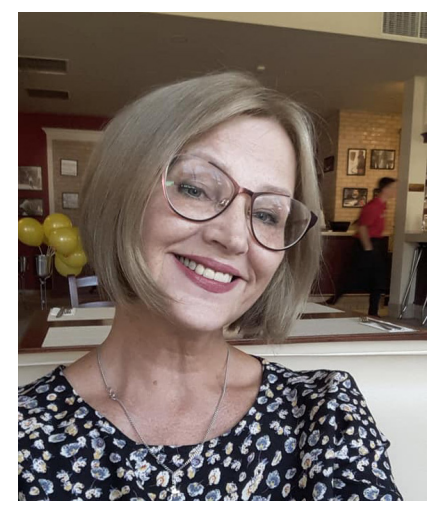

Цель данной статьи - характеристика ценностного представления Тувы в публицистических текстах немецкоязычных СМИ с помощью анализа их модальности. Характер разных типов модальности и их соотношения в тексте привлекают серьезное внимание отечественных лингвистов, начиная с 1990-х годов. Особое значение эта проблема приобретает в медиалингвистике, поскольку текстовая модальность является важнейшим и не всегда явным способом выражения ценностной позиции и субъективной оценки журналистом событий и явлений.

Материалом для исследования послужили 30 статей 2012-2021 г2. о республике Тува в циирровых версиях газет и журналов "Frankfurter Allgemeine Zeitung", "Die Welt", "Explorer”, "Die Tageszeitung”, “Der Spiegel”, “Focus”, “Die Zeit”. Новизна исследования объясняется тем, что языковые средства модальности немецкоязычного текста, особенно публицистического, в России практически не изучены.

В качестве метода и инструмента анализа авторы используют категорию модальной сетки текста и прослеживают с ее помощью формирование аксиологии публикаций о Туве. Результаты анализа показывают, что Тува в новейшем медийном дискурсе Германии представляется не с критических позиций, а как уникальный по своей истории, природе и культуре регион.

Ключевые слова: модальность текста; модальная сетка; публицистический текст; Тува; образ Тувы; немецкие СМИ; Германия; международные отношения

Для цитирования:

Комуцци Л. В., Карпунина И. В. Текстовая модальность как способ ценностного представления Тувы в немецкой публицистике // Новые исследования Тувы. 2021, № 4. С. 89-100. DOI: https://www.doi.org/10.25178/nit.2021.4.7

Комуцци Людмила Владимировна - доктор филологических наук, профессор кафедры «Теория и практика перевода» Института общественных наук и международных отношений Севастопольского государственного университета. Адрес: 299053, Россия, г. Севастополь, ул. Университетская, д. 33. Эл. адрес: 1tataru@yandex.ru

Карпунина Ирина Владимировна - аспирант кафедры английской филологии и межкультурной коммуникации Белгородского государственного национального исследовательского университета. Адрес: 308015, Россия, г. Белгород, ул. Победы, д. 85. Тел: +7 (4722) 24-54-04. Эл. адрес: petrovairina0@yandex.ru. Научный руководитель - доктор филологических наук, проф. Л. В. Комуцци.

KOMUTSTSI, Liudmila Vladimirovna, Doctor of Philology, Chair of Translation Studies, Professor, Institute of Social Sciences and International Relations, Sevastopol State University. Postal address: 33 Universitetskaya St., 299053 Sevastopol, Russian Federation. E-mail: ltataru@yandex.ru ORCID ID: 0000-0002-1412-0201 KARPUNINA, Irina Vladimirovna, Post-graduate Student, Department of English Philology and Intercultural Communication, The National Research University “Belgorod State University”. Postal address: 85 Pobedy St., 308015 Belgorod, Russian Federation. Tel.: +7 (4722) 24-54-04. E-mail: petrovairina0@yandex.ru. Research advisor: L. V. Komutstsi, Doctor of Philology. ORCID ID: 0000-0002-1772-7623 


\title{
Text Modality as a Mode of Value-based Representation of Tuva in German Opinion Journalism
}

\author{
Liudmila V. Komutstsi \\ Sevastopol State University, Russian Federation, \\ Irina V. Karpunina \\ Belgorod State University, Russian Federation
}

\begin{abstract}
The aim of the article is to characterize the value representation of Tuva in opinion texts published in German language media by analyzing their modality. The features of different types of modality and their correlations in the text have attracted a close attention of Russian linguists since the 1990s. This issue is of particular importance in media linguistics because textual modality is the most important but not always explicit way of expressing a value standpoint and a journalist's subjective assessment of events and phenomena. The study material consists of 30 articles on the Republic of Tuva published in 2012-2021 in digital versions of newspapers and magazines ("Frankfurter Allgemeine Zeitung", "Süddeutsche Zeitung", "Die Welt", "Explorer", "Die Tageszeitung”, "Der Spiegel", "Focus" and "Die Zeit"). The research is novel because of the fact that the linguistic means of modality in German language texts, especially in opinion pieces, are poorly studied in Russia.

As a method and tool of analysis the authors use the category of the modal grid of the text. With its help they trace the development of the axiology of publications on Tuva. The results of the analysis show that Tuva is presented in the latest media discourse of Germany not from critical perspectives, but as a region that has a unique history, nature and culture.
\end{abstract}

Keywords: modality of the text; modal grid; opinion text; Tuva; image of Tuva; German media; Germany; international relations Research of Tuva, 2021, no. 4, pp. 89-100. (In Russ.). DOI: https://www.doi.org/10.25178/nit.2021.4.7

\section{Введение}

Текстовая модальность является сложной формой кодирования объективных и субъективных суждений о действительности, вымышленной или реальной. Важнейшую роль для ее формирования играют средства выражения аксиологической позиции автора, определяемой его индивидуальными и национально-культурными ценностями. Цель исследования заключается в анализе соотношения разных типов модальности, формирующих аксиологию представления Тувы и тувинцев в СМИ современной Германии. Изучая аксиологическое содержание немецких публицистических статей о России, мы обнаружили, что Сибирь и Тува представлены в них не как объекты политической и идеологической критики, а в другой, этнографической перспективе, окрашенной преимущественно положительными коннотациями.

Актуальность данного исследования заключается в двух аспектах: в описании системы языковых средств модальности немецкоязычного публицистического текста, с другой - в получении новой для медиалингвистики и тувиноведения, лингвистически обоснованной информации об аксиологии представления Тувы в немецких СМИ через модальность как репрезентант ценностной установки автора. Метод исследования основан на лингвистической модели анализа модальной сетки текста как одного из планов точки зрения автора. Дополнительно использован метод контент-анализа тридцати статей, посвященных Туве или упоминающих Туву и тувинцев, опубликованных в период с 2012 по 2021 г. на сайтах газет и журналов "Frankfurter Allgemeine Zeitung”, "Süddeutsche Zeitung”, 
“die Welt”, “Expert”, “Die Tageszeitung”, “Der Spiegel”, “Focus”. Этот корпус текстов (см. таб. 1) собран методом отбора по ключевому слову «Тuwa» с дальнейшим переходом на официальные страницы перечисленных изданий.

Таблица 1. Тува и тувинцы в немецкой публицистике (2012-2021).

Table 1. Tuva and Tuvans in German Opinion Journalism (2012-2021).

\begin{tabular}{|c|c|c|c|c|c|}
\hline & Автор & Название статьи & Издание & Дата & Гиперссылка \\
\hline 1 & $\begin{array}{l}\text { B. von } \\
\text { Imhoff }\end{array}$ & $\begin{array}{l}\text { Minus } 57 \text { Grad - Mega- } \\
\text { Kälte lähmt Russland/ } \\
\text { Минус } 57 \text { - Мега-Холод } \\
\text { парализует Россию }\end{array}$ & Die Welt & 22.12.2012 & $\begin{array}{l}\text { https://www.welt.de/vermischtes/ } \\
\text { article112198663/Minus-57-Grad-Mega- } \\
\text { Kaelte-laehmt-Russland.html }\end{array}$ \\
\hline 2 & - & $\begin{array}{l}\text { Ein so schwerer Hecht } \\
\text { könnte nicht schwimmen/ } \\
\text { Такая тяжелая щука не } \\
\text { поплывет }\end{array}$ & Die Welt & 29.07.2013 & $\begin{array}{l}\text { https://www.welt.de/politik/ausland/ } \\
\text { article118485702/Ein-so-schwerer-Hecht- } \\
\text { koennte-nicht-schwimmen.html }\end{array}$ \\
\hline 3 & J. Uthoff & $\begin{array}{l}\text { Auf dem Broadway von } \\
\text { Pyatigorsk/На Бродвей } \\
\text { из Пятигорска }\end{array}$ & $\begin{array}{l}\text { Die } \\
\text { Tageszeitung }\end{array}$ & 28.09 .2013 & https://taz.de/!446131/ \\
\hline 4 & - & $\begin{array}{l}\text { Sibiriens «Pharaonen»/ } \\
\text { Сибирские «Фараоны» }\end{array}$ & Focus & 13.11 .2013 & $\begin{array}{l}\text { https://www.focus.de/wissen/natur/ } \\
\text { sibiriens-pharaonen-archaeologie_ } \\
\text { id_2023850.html }\end{array}$ \\
\hline 5 & - & $\begin{array}{l}\text { Wochenendtrip in } \\
\text { Sibirien/Выходные в } \\
\text { Сибири }\end{array}$ & Focus & 19.11.2013 & $\begin{array}{l}\text { https://www.focus.de/panorama/welt/ } \\
\text { wochenendtrip-in-sibirien-russlands- } \\
\text { praesident-wladimir-putin-faengt-21-kilo- } \\
\text { hecht_id_3021915.html }\end{array}$ \\
\hline 6 & - & $\begin{array}{l}\text { Weltmusikerinnen aus } \\
\text { Tuwa können nicht beim } \\
\text { Palais Sommer spielen/ } \\
\text { Мировые музыканты } \\
\text { из Тувы не смогут } \\
\text { выступать на Palais } \\
\text { Sommer }\end{array}$ & Die Welt & 07.08 .2014 & $\begin{array}{l}\text { https://www.welt.de/regionales/sachsen/ } \\
\text { article130989753/Weltmusikerinnen- } \\
\text { aus-Tuwa-koennen-nicht-beim-Palais- } \\
\text { Sommer-spielen.html }\end{array}$ \\
\hline 7 & T. Mauch & Musik/Музыка & $\begin{array}{l}\text { Die } \\
\text { Tageszeitung }\end{array}$ & 12.03.2015 & https://taz.de/!212783/ \\
\hline 8 & A. Balzer & $\begin{array}{l}\text { Vom Brunftschrei in } \\
\text { Trance versetzt/ Введен } \\
\text { в транс призывным } \\
\text { криком }\end{array}$ & $\begin{array}{l}\text { Die } \\
\text { Tageszeitung }\end{array}$ & 16.03.2015 & https://taz.de/!210787/ \\
\hline 9 & D. Stolpe & $\begin{array}{l}\text { Sibirien ist nur karg und } \\
\text { kalt? Von wegen/ Сибирь } \\
\text { лишь пустынна и } \\
\text { холодна? Как бы не так }\end{array}$ & Die Welt & 24.07.2015 & $\begin{array}{l}\text { https://www.welt.de/reise/Fern/ } \\
\text { article144401614/Sibirien-ist-nur-karg- } \\
\text { und-kalt-Von-wegen.html }\end{array}$ \\
\hline 10 & I. Naymushin & $\begin{array}{l}\text { Im Dunst der } \\
\text { Schamanen/B дымке } \\
\text { шаманов }\end{array}$ & Die Zeit & 10.01.2016 & $\begin{array}{l}\text { https://www.zeit.de/entdecken/ } \\
\text { reisen/2016-01/sibirien-schamane-rituale- } \\
\text { fs }\end{array}$ \\
\hline
\end{tabular}




\section{НОВЫЕ ИССЛЕДОВАНИЯ ТУВЫ}

Www.nit.tuva.asia
№4

2021
THE NEW RESEARCH OF TUVA

Novye issledovaniia Tuvy

\begin{tabular}{|c|c|c|c|c|c|}
\hline 11 & - & $\begin{array}{l}\text { Ein toller Hecht!/ } \\
\text { Чудесная щука! }\end{array}$ & Die Zeit & 6.08 .2016 & $\begin{array}{l}\text { https://www.zeit.de/politik/ } \\
\text { ausland/2017-08/putin-bergsee-russland-fs }\end{array}$ \\
\hline 12 & - & $\begin{array}{l}\text { Tserin allein im Wald/ } \\
\text { Церин одна в лесу }\end{array}$ & Spiegel & 23.09 .2016 & $\begin{array}{l}\text { https://www.spiegel.de/panorama/ } \\
\text { russland-kleinkind-ueberlebt-tagelang-in- } \\
\text { sibiriens-wildnis-a-1113617.html }\end{array}$ \\
\hline 13 & S. Gollnow & $\begin{array}{l}\text { Ich hatte keine Angst/ } \\
\text { Мне не было страшно }\end{array}$ & Focus & 24.09 .2016 & $\begin{array}{l}\text { https://www.focus.de/panorama/welt/ } \\
\text { ich-hatte-keine-angst-ernaehrte-sich-von- } \\
\text { schokoriegeln-dreijaehriger-ueberlebt-drei- } \\
\text { tage-im-wald_id_5981042.html }\end{array}$ \\
\hline 14 & I. Naymushin & $\begin{array}{l}\text { Im Dunst der Schamanen/ } \\
\text { В дымке шаманов }\end{array}$ & Die Zeit & 10.01 .2016 & $\begin{array}{l}\text { https://www.zeit.de/entdecken/ } \\
\text { reisen/2016-01/sibirien-schamane-rituale- } \\
\text { fs }\end{array}$ \\
\hline 15 & - & $\begin{array}{l}\text { Allein unter Wölfen/ } \\
\text { Одна среди волков }\end{array}$ & $\begin{array}{l}\text { Frankfurter } \\
\text { Allgemeine }\end{array}$ & 14.03 .2017 & $\begin{array}{l}\text { https://fazarchiv.faz.net/payment/ } \\
\text { faznet?key=/-gun-8vvce }\end{array}$ \\
\hline 16 & S.Orth & $\begin{array}{l}\text { Zehn Tipps für Russland/ } \\
10 \text { советов о России }\end{array}$ & Spiegel & 18.05 .2017 & $\begin{array}{l}\text { https://www.spiegel.de/reise/europa/ } \\
\text { russland-zehn-insider-tipps-fuer-eine- } \\
\text { russland-reise-a-1147827.html }\end{array}$ \\
\hline 17 & M. Zips & $\begin{array}{l}\text { Aus Anglersicht ist das } \\
\text { völlig uninteressan }\end{array}$ & $\begin{array}{l}\text { Süddeutsche } \\
\text { Zeitung }\end{array}$ & 9.08 .2017 & $\begin{array}{l}\text { https://www.sueddeutsche.de/panorama/ } \\
\text { wladimir-putin-beim-angeln-aus- } \\
\text { anglersicht-ist-das-voellig-uninteressant- } \\
\text { 1.3622514?reduced=true }\end{array}$ \\
\hline 18 & A. Nikolsky & $\begin{array}{l}\text { Bilder des Tages/ } \\
\text { Картины дня }\end{array}$ & $\begin{array}{l}\text { Süddeutsche } \\
\text { Zeitung }\end{array}$ & 27.08 .2017 & $\begin{array}{l}\text { https://www.sueddeutsche.de/leben/ } \\
\text { momentaufnahmen-im-august-bilder-des- } \\
\text { tages-1.3611947 }\end{array}$ \\
\hline 19 & N. Kellner & $\begin{array}{l}\text { Wanderer zwischen } \\
\text { Orient und Okzident/ } \\
\text { Странники между } \\
\text { Востоком и Западом }\end{array}$ & $\begin{array}{l}\text { Süddeutsche } \\
\text { Zeitung }\end{array}$ & 8.11 .2017 & $\begin{array}{l}\text { https://www.sueddeutsche.de/muenchen/ } \\
\text { erding/stammesfuehrer-und-schamane- } \\
\text { wanderer-zwischen-orient-und- } \\
\text { okzident-1.3741458 }\end{array}$ \\
\hline 20 & - & $\begin{array}{l}\text { Kehlgesang/Горловое } \\
\text { пение }\end{array}$ & $\begin{array}{l}\text { Die } \\
\text { Tageszeitung }\end{array}$ & 18.11.2017 & https://taz.de/!5460627/ \\
\hline 21 & $\begin{array}{l}\text { H. } \\
\text { Patzinger }\end{array}$ & $\begin{array}{l}\text { Welche Bücher der } \\
\text { „deutsche Indiana Jones“ } \\
\text { empfiehlt / Какие книги } \\
\text { посоветует «немецкий } \\
\text { Индиана Джонс» }\end{array}$ & Die Welt & 14.12.2017 & $\begin{array}{l}\text { https://www.welt.de/kultur/ } \\
\text { literarischewelt/article171561988/Welche- } \\
\text { Buecher-der-deutsche-Indiana-Jones- } \\
\text { empfiehlt.html }\end{array}$ \\
\hline 22 & I. Naymushin & $\begin{array}{l}\text { Kamele im Schnee/ } \\
\text { Верблюды в снегу }\end{array}$ & Spiegel & 19.02.2018 & $\begin{array}{l}\text { https://www.spiegel.de/fotostrecke/ } \\
\text { russland-in-der-republik-tuwa-in-sibirien- } \\
\text { leben-die-nomaden-fotostrecke-158592. } \\
\text { html }\end{array}$ \\
\hline
\end{tabular}




\begin{tabular}{|c|c|c|c|c|c|}
\hline 23 & - & $\begin{array}{l}\text { Uns stehen alle Türen } \\
\text { offen/ Нам открыты все } \\
\text { двери }\end{array}$ & Die Zeit & 15.03.2018 & $\begin{array}{l}\text { https://www.zeit.de/politik/ } \\
\text { ausland/2018-03/praesidentschaftswahl- } \\
\text { russland-waehler-fs }\end{array}$ \\
\hline 24 & K. Nagel & Einblick/ Ознакомление & $\begin{array}{l}\text { Die } \\
\text { Tageszeitung }\end{array}$ & 12.08.2018 & https://taz.de/!5517299/ \\
\hline 25 & J. Hans & $\begin{array}{l}\text { Ein sehr menschlicher } \\
\text { Мensch/ Человечный } \\
\text { человек }\end{array}$ & $\begin{array}{l}\text { Süddeutsche } \\
\text { Zeitung }\end{array}$ & 6.09 .2018 & $\begin{array}{l}\text { https://www.sueddeutsche.de/kultur/ } \\
\text { russisches-fernsehen-ein-sehr- } \\
\text { menschlicher-mensch-1.4119718 }\end{array}$ \\
\hline 26 & I. Kaffka & $\begin{array}{l}\text { Diejenigen, die bleiben, } \\
\text { sind zäh/ Те, кто } \\
\text { остается, жесткие }\end{array}$ & Spiegel & 20.04.2019 & $\begin{array}{l}\text { https://www.spiegel.de/panorama/ } \\
\text { gesellschaft/nanna-heitmann-menschen- } \\
\text { rund-um-den-jenissei-a-1257294.html }\end{array}$ \\
\hline 27 & - & $\begin{array}{l}\text { Tuwa - Im Land der } \\
\text { Schamanen/ Тува - в } \\
\text { стране шаманов }\end{array}$ & Explorer & 15.11.2019 & $\begin{array}{l}\text { https://explorer-magazin.com/reise/asien/ } \\
\text { tuwa-im-land-der-schamanen/ }\end{array}$ \\
\hline 28 & - & $\begin{array}{l}\text { Von Nomaden und } \\
\text { Schamanen/ O } \\
\text { кочевниках и шаманах }\end{array}$ & $\begin{array}{l}\text { Süddeutsche } \\
\text { Zeitung }\end{array}$ & 27.11.2019 & $\begin{array}{l}\text { https://www.sueddeutsche.de/muenchen/ } \\
\text { ebersberg/mongolei-in-moosach- } \\
\text { von-nomaden-und-schamanen- } \\
\text { 1.4700827?reduced=true }\end{array}$ \\
\hline 29 & $\begin{array}{l}\text { B. } \\
\text { Brosowsky }\end{array}$ & $\begin{array}{l}\text { Surrealismus mit } \\
\text { Spiegelei/ Сюрреализм с } \\
\text { яичницей }\end{array}$ & $\begin{array}{l}\text { Die } \\
\text { Tageszeitung }\end{array}$ & 12.2.2020 & https://taz.de/!5659698/ \\
\hline 30 & S. Krüger & $\begin{array}{l}\text { Licht an - und die } \\
\text { Grenzen sind einfach } \\
\text { weg/ Включи свет и } \\
\text { границы исчезнут }\end{array}$ & Die Welt & 03.02 .2021 & $\begin{array}{l}\text { https://www.welt.de/reise/Fern/ } \\
\text { article225443557/Reisen-auf-dem-Globus- } \\
\text { Licht-an-und-die-Grenzen-sind-weg.html }\end{array}$ \\
\hline
\end{tabular}

\section{Аксиологическое содержание и модальная сетка публицистического текста}

Медиадискурс сегодня играет главную роль в определении языковых норм и, соответственно, в формировании и распространении культурных интерпретаций и конструкций. Транслируя и преобразовывая информацию, журналистские тексты создаются с помощью особых приемов, направляющих декодирование получателями смысловых конструкций так, чтобы они встраивались в их собственный горизонт жизненного мира (Porombka, 2007: 197). Для художественно-публицистических жанров журналистики, охарактеризованных А. А. Тертычным (Тертычный, 2017), а в немецкой теории журналистики В. фон Ла Рошем (von La Roche, 1976: 59), характерен публицистический функциональный стиль, который используется в сферах политических, экономических, культурных и иных общественных отношений (Жеребило, 2010: 293). Публицистическим текстам в любой исторический период присущи определенные константы: шкала ценностей, оценочность, идеологема, образ автора (Серпикова, 2017: 29-48).

Оценочность отражает оценки, то есть «действия субъекта: приписывание положительных или отрицательных свойств тому или иному объекту, выражение отношения к данному объекту, фиксацию объекта на оценочной шкале и в аксиологическом поле» (Марьянчик, 2011: 101). В зависимости от степени участия автора и по способу выражения, оценка может быть имплицитной, без прямых вербальных показателей, и эксплицитной - однозначной интерпретацией, подтвержденной вербально.

Аксиологическая (ценностная) структура текста эксплицируется различными языковыми средствами, ее динамичность и гибкость обусловлены точкой зрения, ценностными ориентациями самого автора. 
Определение понятия «ценность» и выявление ее национальной специфики - задача, которая лежит в сфере культурологии и философии, но ее содержание необходимо понимать и лингвисту, занимающемуся проблемами аксиологии и модальности. То, что индивид определяет как «ценностное», является внутренней определяющей его как осознанного, так и неосознанного поведения (Грибакин, 2002: 367). По содержанию различаются вещные, этические, эстетические и логические ценности, соотносимые содержательно с понятиями добра, прекрасного, истины (Лингвистика и аксиология ... , 2011: 28). Одной из форм репрезентации ценностей в тексте выступают средства аксиологической модальности. Выбор этих средств определяется авторской точкой зрения, которую читательская аудитория без труда определяет благодаря закодированным в них ценностным ориентациям.

Аксиологическая маркированность представляется неотъемлемой частью феномена модальности как транслятора культурных кодов, нравственных приоритетов и ценностных представлений как отдельного индивида, так и социума в целом. Ценность, зафиксированная в сознании носителя языка как аксиологический концепт или ценностный (оценочный) компонент концептуальной единицы, выступает основанием оценки, и сама является объектом оценивания (Марьянчик, 2013: 7).

Под языковой модальностью принято понимать «функционально-семантическую категорию, выражающую разные виды отношения высказывания к действительности, а также разные виды субъективной квалификации сообщаемого» (Ляпон, 1998: 303). Модальность текста - линейная категория, формируемая комплексом лексических (оценочные слова), синтаксических (риторические вопросы, инверсия, параллелизм) и грамматических средств (наклонение, модальные глаголы) средств.

Для изучения модальности современного немецкого медиатекста мы используем концепцию модальности Л. В. Комуцци (Татару). Согласно автору, модальность текста представляет собой дискурсивную модель, структура которой отражает динамику авторской точки зрения. Каждый ее сегмент - абзац, предложение или клауза (синтагма) - содержит суждение или мнение о мире, определяемое разными типами модальности и позицией автора - внешней или внутренней. Всего выделяется шесть типов модальности, причем доминирует в тексте один из них: эпистемологическая, эвиденциальная, эмотивная, обусловливающая, гипотетическая и оценочная (аксиологическая) (Татару, 2011: 188).

Эпистемологическая модальность (ЭпМ) выражает отношения «знания/незнания», «уверенность/неуверенность», выводы из наблюдаемых и общеизвестных фактов (там же: 188). Маркерами ее в немецком тексте являются Indikativ, Konjunktiv II для выражения потенциального, ирреального, неуверенности или желания, глаголы (können 'мочь, уметь', müssen 'должен', dürfen 'можно, иметь разрешение', mögen ‘любить', wollen 'хотеть', sollen ‘должен’, warden ‘становиться’, brauchen 'нуждаться’), модальные слова и частицы, выражающие степень уверенности, сомнения. Последние, в свою очередь, Г. Дрессигер дифференцирует в зависимости от окрашенности установки говорящего:

1. Индикаторы уверенности - наиболее яркие маркеры эпистемологической модальности, выражающие отношение к сказанному. Сюда относятся такие слова, как augenscheinlich 'явный', bekanntlich 'как известно', keinesfalls ‘ни в коем случае', selbstverständlich ‘само собой разумеется’, wirklich ‘действительно', zweifellos ‘без сомнения’ и т. д.;

2. Индикаторы предположения - anscheinend 'очевидно, möglicherweise 'быть может', sicherlich ‘несомненно', vermutlich 'предположительно', vielleicht ‘возможно', wahrscheinlich 'вероятно', wohl ‘пожалуй’ и др.;

3. Индикаторы дистанцирования указывают на то, что автор с долей сомнения передает информацию от третьего лица - angeblich 'предполагаемый’, vermeintlich 'мнимый', vorgeblich 'мнимый, так называемый’ и др.;

4. Индикаторы эмотивности, указывающие на эмоциональное состояние говорящего - ärgerlicherweise ‘досадным образом’, bedauerlicherweise ‘к сожалению’, glücklicherweise ‘счастливым образом’, hoffentlich 'с надеждой’, leider 'к сожалению’ и др.

5. Индикаторы оценки - anständigerweise 'порядочно, значительн, besser 'лучше', dummerweise ‘глупо’, klugerweise ‘умно’, lieber ‘лучше, скореe’, logischerweise ‘логично’, vergeblich (erweise) ‘напрасно’ и др. (Droessiger, 2008: 56-57).

Эвиденциальная модальность (ЭвМ) подразумевает изложение доказательств того или иного факта или суждения. К доказательствам автор может прийти самостоятельно, либо передать их от 
третьих лиц. Маркерами выступают глаголы перцептивной деятельности (hören 'слышать', sehen 'видеть', fühlen 'чувствовать', етрfinden 'чувствовать, ощущать' и др.), модальные глаголы, модальные слова, слова отстранения и сомнения, чужая речь.

Эмотивная модальность (ЭМ) не является основной, выступает совместно с другими типами модальности. Основная функция - выражение эмоций автора по отношению к определенной ситуации/событию. Маркерами являются восклицательные предложения (Was für ein schöner Tag! 'Какой прекрасный день!'), эмотивная лексика, глаголы ощущения и чувств (lieben 'любить', fühlen 'чувствовать' и др.).

Обусловливающая модальность (ОбМ) связана с понятиями «разрешение», «запрет», «необходимость», «способность», «волеизъявление». Тексты, где превалирует данный тип модальности, связаны с областями законодательства и морали. К маркерам относятся модальные глаголы и волеизъявительная лексика (wünschen 'желать', erlauben 'разрешать', verbieten ‘запрещать' и др.).

Гипотетическая модальность (ГМ) выражается понятиями «возможность/невозможность», «желание/нежелание». Маркерами являются конструкции с нереальным условием (Konjunktiv) и предположительным следствием, модальные слова, существительные и глаголы со значением «воображения» (sich vorstellen 'представить себе', sich einbilden 'воображать себе', sich ausmalen 'представлять себе' и др.).

Оценочная (аксиологическая) модальность (ОцМ) формируется понятиями «добро/зло», «хорошее/плохое», связанными с ценностями говорящего. Маркерами выступает оценочная лексика (wunderbar 'чудесно', eigenartig 'своеобразно' и др.), ключевые слова-символы, выражающие ценностную установку автора и слова-идеологемы (Татару, 2011: 188-190; Татару, 2012: 63).

Следует сказать, что однозначного мнения по вопросу четкого разделения понятий аксиологической и оценочной модальности нет. Для характеристики модальности больше подходит используемый в лингвистике термин «оценочная». Содержательно она является аксиологической, выражающей субъективные суждения о ценностях и связанных с ними лицах, событиях или явлениях как «хороших» или «плохих».

Важно также понимать, что типы модальности взаимодействуют друг с другом, и в цепочке этого взаимодействия сегменты текста периодически окрашиваются оценочно, гипотетически, эмотивно либо обусловливающе, что зачастую представлено в рамках одного и того же предложения.

Чередование сегментов текста, определяемых разными типами модальности, складывается в модальную сетку текста - прагматическую категорию, определяемую изначальной установкой автора на характер представления действительности и формирующую стиль, тон и смысл текста. Модальная сетка выполняет важную функцию в восприятии текста - она регулирует «первичное восприятие ритма субъективной модальности и определяет схему ожиданий возможной последовательности оценочных позиций» (Татару, 2011: 190). Типы модальности меняются от сегмента сетки к сегменту, и в сумме они дают оценку фактов как «хороших» / «плохих». Соотношение объективной и субъективной модальностей выражается как соотношение немаркированной модальности изъявительного наклонения и нейтральной лексики (ЭвМ и ЭпМ) и маркированных форм сослагательного наклонения, инверсии, эмотивной, оценочной, образной лексики.

\section{Анализ модальности публицистических текстов о Туве и тувинцах}

Рассмотренные СМИ включают и либерально-консервативное направление (“Frankfurter Allgemeine Zeitung”, “Die Welt”, “Süddeustche Zeitung“, “Focus“), и левое (“Tageszeitung“, “Der Spiegel“). Журнал "Explorer” посвящен исключительно тематике путешествий и новостям из мира техники и не претендует на политическую направленность. Разные политические платформы изданий, степень зависимости их от власти не отразились на аксиологическом ракурсе рассмотренных публикаций, что говорит о явной привлекательности Тувы для немцев.

Рассмотрим, как происходит динамика сегментов модальной сетки в следующем фрагменте статьи "Sibirien ist nur karg und kalt? Von wegen" / «Сибирь лишь пустынна и холодна? Как бы не так» из онлайн издания “Die Welt”. Автор, Даниэль Стольпе, совершивший путешествие в Туву, разрушает стереотип представления об этом крае как холодном и безжизненном. 
Kysyl bedeutet in der Landessprache so viel wie Rot, und die sowjetische Vergangenheit ist im Stadtbild ebenso wenig zu leugnen wie der mongolische Einfluss in der Bevölkerung (1). Es ist eine arme Stadt, belebt von rund 100.000 Menschen, die alle nicht viel besitzen, aber trotzdem einen glücklichen, ja vergnügten Eindruck machen, wenn sie sich an einem der heißen sibirischen Sommertage in dem Springbrunnen auf dem Leninplatz abkühlen können (2). Heiße sibirische Sommertage? Das ist nur ein Fakt, der der Vorstellung im 6000 Kilometer entfernten Deutschland deutlich widerspricht (3). Nicht öd und karg, sondern von einer einzigartigen Natürlichkeit ist dieser Teil Sibiriens, in dem es im Sommer so heiß werden kann wie in Europa allenfalls in Südspanien oder auf einigen griechischen Inseln (4) ${ }^{1}$.
Кызыл означает в тувинском Красный, и следы советского прошлого в облике города сложно отрицать, также как и следы монгольского влияния в жителях (1). Это бедный город с населением около 100.000 человек, которых не назовешь состоятельными, но которые производят счастливое, позитивное впечатление, когда они остужаются в летнюю сибирскую жару в фонтане на площади Ленина (2). Жаркое сибирское лето? Это просто факт, противоречащий представлению Германии, расположенной за 6000 километров отсюда (3). Не пустынная и скудная, а уникальная в своей естественности часть Сибири, где лето может быть таким же жарким, как и в Европе, возможно на юге Испании или на некоторых греческих островах $(4)^{2}$.

Чередование типов модальности создает ощутимый ритм, в котором за фактологичностью следуют эмоциональные и оценочные значения: ЭпМ - ЭпМ/ЭМ/ОцМ - ЭпМ/ ЭвМ/ОцМ/ЭМ - ЭпМ/ЭвМ/ОцМ

В первой клаузе ЭпМ выражается глаголами настоящего времени в изъявительном наклонении и индикатором степени уверенности/знания автора (wenig zu leugnen 'сложно отрицать'). В следующем предложении автор описывает свое впечатление от Кызыла, используя оценочные эпитеты (arm 'бедный', glücklich 'счастливый’) и формируя антитезу этому «знанию» во втором отрывке с помощью контрастной оценочности. Индикатор эмотивной модальности во второй клаузе - частица Ja 'же', ведь, экспрессивно усиливающая высказывание. Следующая клауза начинается с риторического вопроса, характерного для публицистического стиля и выражающего здесь ОцМ и ЭМ. Риторический вопрос не эксплицирует оценку в чистом виде: намерения автора кроются глубже, чем в повествовательных предложениях. Отрывок содержит и ЭпМ с оттенком уверенности (индикатор deutlich 'отчетливо, ясно'). В четвертой клаузе мы видим сегмент ОцМ, а именно ряд эпитетов, снова отражающих антитезу - не пустынная и необитаемая Сибирь, а своеобразная естественность местных регионов. В анализируемом предложении ОцМ переплетается с ЭпМ и ЭвМ, представленными в тексте модальным глаголом в изъявительном наклонении (kӧnnen 'мочь, уметь') со значением возможности и наречием с оттенком предположения (allenfalls ‘в крайнем случае, пожалуй’). В третьей и четвертой клаузе стереотипные представления о Туве опровергаются действительностью.

Тува в представлении далекой Германии, как пишет Даниэль Стольпе, является холодным краем, однако летом там так же жарко, как на юге Испании или в Греции. Природа характеризуется номинативной фразой с эпитетом einzigartige Natürlichkeit 'уникальная естественность'. Ее положительная коннотация подчеркнута благодаря оппозиции с негативной оценочностью эпитетов, описывающих стереотип (öd, karg ‘пустынный, скудный’). «Естественность» Тувы, то есть ее первозданная природа и счастье, состоящее для жителей Тувы в простых маленьких радостях, образуют главный аксиологический ориентир и перевешивают негативные представления о крае на шкале авторских ценностей.

Рассмотрим биографический очерк “Wanderer zwischen Orient und Okzident” «Странники между Востоком и Западом» о германисте и писателе Галсане Чинаге (монгольском тувинце) и о его проектах возрождения природы западно-монгольской степи. Журналистка Надин Келлер, включает в данный очерк отрывки интервью с Вильмой Брюггерманн, председателем фонда финансовой поддержки Монголии.

\footnotetext{
${ }^{1}$ Sibirien ist nur karg und kalt? Von wegen [Электронный ресурс] // Die Welt. 2015, 24.07. URL: https://www.welt. de/reise/Fern/article144401614/Sibirien-ist-nur-karg-und-kalt-Von-wegen.html?icid=search.product.onsitesearch (дата обращения: 12.08.2021).

2 Здесь и далее перевод с немецкого наш. - И. К.
} 
Tschinags Ziel sind eine Millionen Bäume. 700000 sind schon gepflanzt (1). "Tuwa-Nomaden würden nie die Natur verunreinigen oder einen lebenden Baum fällen“, erklärt Brüggemann (2). Die Verehrung und Dankbarkeit der Tuwiner gegenüber der Natur sei ihre Spiritualität, das Schamanentum (3). Und das neuste Projekt zeigt: Galsan Tschinag denkt ganz getreu seinen Wurzeln (4). ${ }^{1}$
Цель Чинага - (посадить. - И. К.) миллион деревьев. 700000 уже посажены (1). «Кочевники Тувы никогда бы не загрязнили природу и не срубили бы живое дерево», объясняет Брюггерманн (2). Почтение и благодарность по отношению к природе выражается в их духовности, шаманизме (3). Последний проект показывает, что Галсан Чинаг остается верен своим корням (4).

ЭпМ - ЭвМ/ ЭпМ - ЭпМ/ОцМ/Гм - ЭвМ /ЭпМ/ОцМ

Эпистемологичность первых коротких предложений подкрепляется цитатой из интервью, усиливающей и уточняющей значимость проекта в плане его национально-культурной ориентации. Прямая цитата - это знак эвиденциальности, но в самом высказывании Вильмы Брюггерманн ярко проявлена оценочность - положительная характеристика менталитета и ценностного отношения кочевников Тувы к природе. Уверенность автора в невозможности загрязнения природы кочевниками тувинцами Монголии (автор статьи называет их Tuwa-Nomaden) - выражена временным наречием (nie 'никогда') (ЭвМ). В третьей клаузе чередуются три вида модальности. Описывая тувинцев, автор использует существительные, означающие отношение тувинцев к природе, с положительной коннотацией: «почет» (Verehrung), «благодарность» (Dankbarkeit) (ОцМ). Они представлены как следствие духовности и шаманской культуры (ЭпМ, Гм). В последней клаузе при помощи наречия (ganz 'совершенно, полностью') автор усиливает степень своей уверенности в верности Галсана Чинага национальным корням (ЭпМ), ссылаясь при этом на результаты последнего его проекта (ЭпМ вводится предикатом zeigen ‘показывать’ в изъявительном наклонении). Индикатором ОцМ выступает прилагательное (getreu 'верный, преданный') с положительной коннотацией, входящее в состав адъективного словосочетания, актуализирующего ценности «Верность», «Уважение», «Наследование». Ярко выраженная положительная коннотация выбранных лексических средств говорит о позитивнооценочном суждении автора.

Восхищение первозданной природой и культурным наследием Тувы характерно и для статьи “Tuwa - Im Land der Schamanen” «Тува - в стране шаманов», подготовленной редакцией журнала "Explorer“" (без указания авторства). Статья написана в жанре травелога и повествует о путешествии Уте Фогель и Андреаса Блэзе. Пара совершает путешествия по отдаленным уголкам мира на машине. Они проезжали Туву, когда ездили в Монголию, но интерес к неизведанному привел путешественников в этот край снова.

Und wer kennt schon die autonome Republik Tuwa an der mongolischen Grenze (1)? Sibirien ist in den Köpfen vieler Leute immer noch gleichzusetzen mit Kälte, Taiga, Sümpfen, Mücken, Autodiebstahl, Verbannung, russischer Mafia und einer schwer zu verstehenden Sprache (2). Warum nach Tuwa (3)? Wäre da nicht dieser weiße Fleck im russischen Straßenatlas, dann hätte uns Tuwa wahrscheinlich auch nicht neugierig gemacht (4). Die Region ist als einer der am wenigsten bekannten Landstriche Sibiriens mit Sicherheit einen längeren Abstecher wert (5). Grandiose Landschaften, eine jahrtausendealte Tradition mit kulturhistorischen Schätzen, ein lebendiges Nomadentum und eine Mischung aus Buddhismus und dem überall praktizierten Schamanismus prägen Tuwa $(6)^{2}$.

А кому знакома автономная республика Тува, располагающая на границе с Монголией (1)? Сибирь в головах многих людей все еще отождествляется с холодом, Тайгой, болотами, комарами, автомобильными кражами, ссылками, русской мафией и языком, сложным для восприятия (2). Почему в Туву (3)? Если бы не это белое пятно на атласе автомобильных дорог России, вряд ли бы мы заинтересовались Тувой (4). Этот регион как один из наименее известных районов Сибири однозначно заслуживает более длительного посещения (5). Грандиозные ландшафты, тысячелетняя традиция, культурно-исторические сокровища, сохранившийся кочевой образ жизни и смесь буддизма с повсеместно практикуемым шаманизмом. Все это накладывает особый отпечаток на Туву (6).

ЭпМ/ОцМ/ЭМ - ЭвМ/ОцМ - ЭпМ/ЭМ - ЭвМ/Гм/ЭМ - ЭвМ/ОцМ - ЭвМ/ОцМ/ЭМ

\footnotetext{
${ }^{1}$ Wanderer zwischen Orient und Okzident [Электронный ресурс] // Süddeutsche Zeitung. 2017, 8.11. URL: https:// www.sueddeutsche.de/muenchen/erding/stammesfuehrer-und-schamane-wanderer-zwischen-orient-undokzident-1.3741458 (дата обращения: 14.08.2021).

2 Tuwa - Im Land der Schamanen [Электронный ресурс] // Explorer. 2019, 15.11. URL: https://explorer-magazin. com/reise/asien/tuwa-im-land-der-schamanen/ (дата обращения: 15.08.2021).
} 
Первая и третья клаузы представляют собой риторические вопросы, комплексно объединяющие несколько типов модальностей (ЭпМ/ОцМ/ЭМ). Их интенциональный компонент переплетается с рядом эмоциональных и модальных коннотаций (см.: Стеля, 2006: 70): пробуждение интереса, сомнение. Во второй клаузе дается перечисление стереотипных ассоциаций с Сибирью (холод, тайга, болота, комары - ЭвМ), некоторые из которых обладают выраженной негативной коннотацией (угон автомобилей, ссылка, малопонятный язык) (ОцМ). Неизведанность Тувы подогревает интерес к исследованию данного региона, сообщает автор (neugierig ‘любопытный’ - ЭМ). Формы Konjunktiv II (wäre, hätte) являются индикаторами ГМ в четвертой клаузе. Маркером ЭвМ с оттенком предположения выступает наречие wahrscheinlich ('вероятно'). Представляя достоинства Тувы, автор выражает уверенность (mit Sicherheit 'с уверенностью' - ЭвМ), что для Тувы как для наименее известного региона Сибири (am wenigsten bekannten) стоит планировать более длительные поездки (einen längeren Abstecher wert). Индикатором ОцМ в пятой клаузе выступают сравнительная и превосходная степени прилагательных. В последней клаузе ОцМ и ЭМ проявляются в использовании эпитетов и существительных (grandiose 'грандиозный', eine jahrtausendealte Tradition 'тысячелетняя традиция', kulturhistorische Schätze 'культурно-исторические сокровища').

Еще один травелог с метафоричным названием “Im Dunst der Schamanen” «B дымке шаманов» рассказан Ильей Наймушиным в стиле, соединяющем эпическое повествование с блоговыми записями и фотографиями. Информация о переводчике в статье отсутствует.

An der Grenze zur Mongolei, am südlichen Ende Sibiriens, liegt die russische Republik Tuwa (1). Ihre Bewohner ziehen mit ihren Jurten zwischen Steppe und Gebirge umher (2). Außer der Viehzucht haben sie nicht viel (3). Nur den festen Glauben an die Geister ihres Volks und das Vertrauen in ihren Schamanen (4). Die helfen ihnen nicht nur in Schicksalsfragen, sondern auch gegen Krankheiten (5) ${ }^{1}$.
В южной части Сибири, на границе с Монголией, располагается республика Тува (1). Ее жители перемещаются вместе с их юртами от степей к горам (2). Животноводство - это все, что у них есть (3). Лишь твёрдая вера в духов и доверие своим шаманам (4) помогают этому народу решать судьбоносные вопросы и бороться с болезнями (5).

ЭпМ - ЭпМ - ЭпМ/ОцМ - ЭпМ - ЭпМ

О географическом расположении республики, кочевом образе жизни и верованиях местных жителей автор повествует, используя, в основном, эпистемологическую модальность, но эпический стиль (инверсия) и экзотическая лексика, означающая атрибуты их быта (Jurten) придает знанию оценочность. Вера в духов и шаманов (ЭпМ с индикатором оценочности - fest 'твердый, крепкий') предстает как духовная ценность, помогающая и в практическом решении серьезных жизненных проблем (ЭпМ/ОцМ).

Соотношение типов модальности в текстах рассмотренных статей представлено в диаграмме (диаграмма 1).

Анализ динамики модальной сетки на примере рассмотренных тридцати немецких публицистических текстов, посвященных Туве и тувинцам, показывает доминирование в них эпистемологической модальности, то есть фактуальной информации, основанной на знании или неполном знании региона. Частотны оценочная, и эмотивная модальности, которые отражают субъективные суждения авторов о ценностях, разделяемых жителями этого края.

Рассмотрев весь наш корпус по методу модальной сетки, мы показали детально процедуру анализа на ряде фрагментов из нескольких статей, взятых из разных изданий. Анализ всех публикаций позволяет понять, что в них практически отсутствует политическая и социальная проблематика, взгляды авторов фокусируются на климатических, природно-ландшафтных и этнокультурных аспектах, подчеркивающих уникальность, экзотичность, богатство истории и культуры края. Это важный и для нашего исследования, и для тувиноведения факт, говорящий о том, что читательскую аудиторию Германии интересуют именно историко-культурное и географическое разнообразие этого

\footnotetext{
${ }^{1}$ Im Dunst der Schamanen [Электронный ресурс] // Die Zeit. 2016, 10.01. URL: https://www.zeit.de/entdecken/ reisen/2016-01/sibirien-schamane-rituale-fs/ (дата обращения: 15.08.2021).
} 


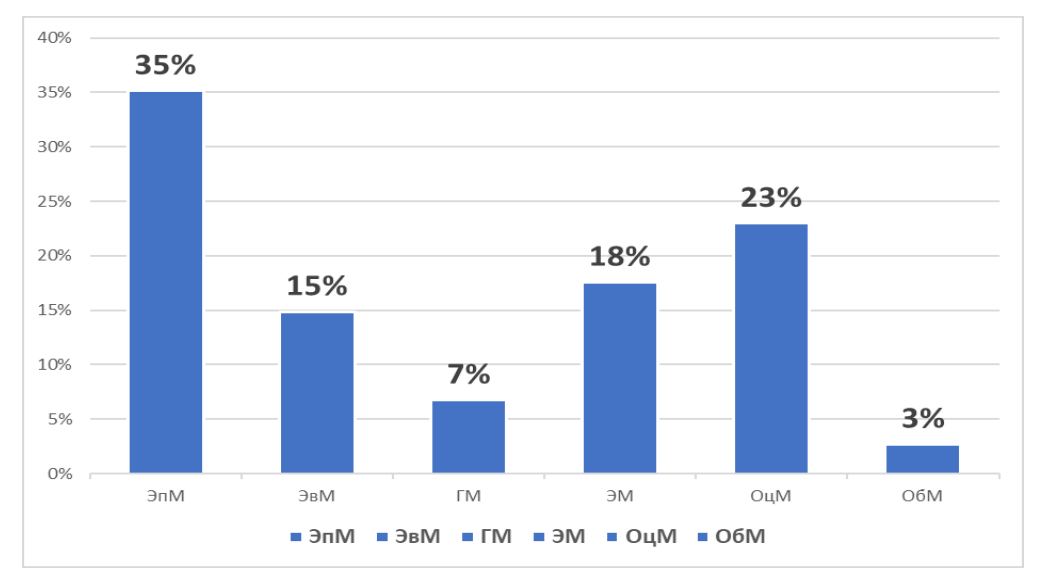

Диаграмма 1. Соотношение типов модальности в 30 статьях немецких СмИ о Туве.

Diagram 1. Proportion of the types of modality in 30 articles on Tuva published in German mass media ${ }^{1}$.

региона, далекого и неведомого, а СМИ учитывают этот интерес и искренне, по нашим наблюдениям, восхищаются его уникальным разнообразием и верностью тувинцев духовным и природным ценностям.

\section{Заключение}

Мы показали, что в дискурсе немецких СМИ Тува представлена как регион, привлекающий внимание своим уникальным культурно-историческим наследием и природным ландшафтом, которые определяют его ценностное содержание. В фокусе внимания авторов такие ценностные аспекты жизни тувинцев, как «Природа», «Буддизм», «Шаманизм», «Уважение», «Номадизм», «Преемственность традиций». Учитывая достаточно холодный климат политических, экономических и культурных отношений между Россией и Германией в настоящий период, мы могли ожидать обратной, критической установки немецких СМИ на представление реалий жизни в Туве как одном из регионов нашей страны. То, что этого не происходит ни в одном из изданий, меняет наше представление о том, что в немецком медиадискурсе (онлайн газетах и журналах) не должно быть места позитивным материалам о России. Изучение модальности и других его языковых характеристик, соответственно, важно и перспективно не только для медиалингвистики, но и для теории журналистики, культурологии, политологии, социологии и других гуманитарных наук.

\section{СПИСОК ЛИТЕРАТУРЫ}

Грибакин, А. В. (2002) Ценностный мир человека и его судьба (лекция 20) // Двадцать лекций по философии : учеб. пособие / отв. ред. И. Я. Лойфман. 2-е изд. Екатеринбург : Банк культурной информации. 367 с. С. 367-394.

Жеребило, Т. В. (2010) Словарь лингвистических терминов. 5-е изд., испр. и доп. Назрань : ООО «Пилигрим». 486 c.

Ляпон, Н. В. (1998) Модальность // Языкознание. Большой энциклопедический словарь / гл. ред. В. Н. Ярцева. М. : Большая Российская энциклопедия. 682 с. С. 303-304.

Лингвистика и аксиология. Этносемиометрия ценностных смыслов (2011) / Е. Ф. Серебренникова и др. М. : Тезаурус. 352 с.

Марьянчик, В. А. (2011) Оценка как категория текста // Вестник Северного (Арктического) федерального университета. Серия: Гуманитарные и социальные науки. № 1. С. 100-102.

Марьянчик, В. А. (2013) Аксиологическая структура медиа-политического текста: лингвостилистический аспект : дисс. ... д-ра филол. н. Архангельск. 382 с.

\footnotetext{
${ }^{1}$ Показатели диаграммы являются результатом статистической обработки 30 текстов. Процентное содержание каждого типа модальности рассчитывалось по формуле X= B*100\% : A (X - искомый показатель, В - число употреблений одного типа модальности в текстах, А - число всех случаев использования модальности в них. Общее число клауз в 30 статьях - 753, из них тех, в которых представлена ЭпМ - 264 (В - 35\%); ЭвМ 113 (15\%); ГМ - 53 (7\%); ЭМ - 136 (18\%); ОцМ - 173 (23\%); ОбМ - 23 (3\%).
} 
Серпикова, М. Б. (2017) Язык и стиль СМИ : курс лекций. М. : РУТ (МИИТ). 333 с.

Стеля, С. С. (2006) Просодические средства выражения модальности в риторическом вопросе в немецком языке // Веснік Беларускага дзяржаўнага універсітэта. Серия. 4. № 3. С. 68-74.

Татару, Л. В. (2011) Нарратив и культурный контекст. М. : URSS. 287 с.

Татару, Л. В. (2012) Нарративная модальность американских и российских таблоидных историй // Новый филологический вестник. № 1 (20). С. 56-67.

Тертычный, А. А. (2017) Жанры периодической печати : учеб. пособие для вузов. 6-е изд., испр. и доп. М. : Аспект Пресс. 320 с.

Droessiger, G. (2008) Zu Ausdrucksmitteln der epistemischen Modalität im Deutschen und Litauischen. Untersuchungen zur Gesprächssorte Interview im Rahmen eines kommunikativ-pragmatischen. Modalitätskonzepts. Doktordissertation. Universität Vilnius. 196 S.

Porombka, S. (2007) Journalistische Formate // Handbuch Literaturwissenschaft, Bd. 2: Methoden. Stuttgart: Metzler. S. 194-198.

von La Roche, W. (1976) Einführung in den praktischen Journalismus: Mit genauer Beschreibung aller Ausbildungswege: Deutschland, Österreich, Schweiz. München : P. List. 247 S.

Дата поступления: 02.09.2021 2.

\section{REFERENCES}

Gribakin, A. V. (2002) Tsennostnyi mir cheloveka i ego sud'ba (lektsiia 20) [The value world of the man and its destiny (Lecture 20)]. In: Dvadtsat' lektsii po filosofii [Twenty lectures on philosophy] : A study guide / ed. by I. Ya. Loifman. $2^{\text {nd }}$ ed. Yekaterinburg, Cultural Information Bank. 407 p. Pp. 367-394. (In Russ.).

Zherebilo, T. V. (2010) Slovar' lingvisticheskikh terminov [Dictionary of linguistic terms]. $5^{\text {th }}$ ed. Nazran, OOO Piligrim. 486 p. (In Russ.).

Liapon, N. V. (1998) Modal'nost' [Modality]. In: Iazykoznanie. Bol'shoi entsiklopedicheskii slovar' [Linguistics. The great encyclopedic dictionary] / ed. by V. N. Yartsev. Moscow, Bol'shaia rossiiskaia entsiklopediia Publ. 682 p. Pp. 303-304. (In Russ.).

Lingvistika i aksiologiia. Etnosemiometriia tsennostnykh smyslov [Linguistics and axiology. Ethnosemiometry of value meanings] (2011) / E. F. Serebrennikova et al. Moscow, Tezaurus Publ. 352 p. (In Russ.).

Maryanchik, V. A. (2011) Otsenka kak kategoriia teksta [Evaluation as a category of text]. Vestnik Severnogo (Arkticheskogo) federal'nogo universiteta. Seriia: Gumanitarnye i sotsial'nye nauki, no. 1, pp. 100-102. (In Russ.).

Maryanchik, V. A. (2013) Aksiologicheskaia struktura media-politicheskogo teksta: lingvostilisticheskii aspekt [Axiological structure of the media and political text: The linguistic and stylistic aspect]: Diss.... Doctor of Philology. Arkhangelsk. 382 p. (In Russ.).

Serpikova, M. B. (2017) Iazyk i stil' SMI [Language and style of mass media] : A course of lectures. Moscow, Russian University of Transport (Moscow Institute of Transport Engineers) Publ. 333 p. (In Russ.).

Stelia, S. S. (2006) Prosodicheskie sredstva vyrazheniia modal'nosti v ritoricheskom voprose v nemetskom iazyke [Prosodic means of expressing modality in a rhetorical question in the German language]. Vesnik Belaruskaga dziarzhay̆naga universiteta, seriia 4, no. 3, pp. 68-74. (In Russ.).

Tataru, L. V. (2011) Narrativ i kul'turnyi kontekst [Narrative and cultural context]. Moscow, URSS Publ. 287 p. (In Russ.).

Tataru, L. V. (2012) Narrativnaia modal'nost' amerikanskikh i rossiiskikh tabloidnykh istorii [Narrative modality of American and Russian tabloid stories]. Novyi filologicheskii vestnik, no. 1 (20), pp. 56-67. (In Russ.).

Tertychnyi, A. A. (2017) Zhanry periodicheskoi pechati [Genres of periodicals] : A study guide for HEIs. $6^{\text {th }}$ ed., revised and enlarged. Moscow, Aspekt Press. 320 p. (In Russ.).

Droessiger, G. (2008) Zu Ausdrucksmitteln der epistemischen Modalität im Deutschen und Litauischen. Untersuchungen zur Gesprächssorte Interview im Rahmen eines kommunikativ-pragmatischen. Modalitätskonzepts : Doctoral Diss. Vilnius, Vilnius University. 196 S. (In Germ.).

Porombka, S. (2007) Journalistische Formate. In: Handbuch Literaturwissenschaft. Stuttgart, Metzler. Bd. 2: Methoden. S. 194-198. (In Germ.).

von La Roche, W. (1976) Einführung in den praktischen Journalismus: Mit genauer Beschreibung aller Ausbildungswege: Deutschland, Österreich, Schweiz. München, P. List. 247 S. (In Germ.). 